\title{
Classroom Monitoring Vocabulary Acquisition Based on Cognitive Semantics
}

\author{
Liao Gaogao \\ Faculty of Foreign Studies \\ Jiangxi University of Science and Technology \\ Ganzhou, Jiangxi \\ e-mail:lggv@163.com
}

\author{
Zong Xueping \\ Faculty of Foreign Studies \\ Jiangxi University of Science and Technology \\ Ganzhou, Jiangxi \\ e-mail:lggv@163.com
}

\begin{abstract}
To achieve effective vocabulary acquisition, a proper classroom monitoring is very important and necessary in language teaching and learning. This paper begins with the introduction of some basic and related theories. Then, based on these theories, this paper analyses monitoring vocabulary classroom teaching and learning from the angle of cognitive psychology and cognitive semantics theories so as to provide implications for the lexical development.
\end{abstract}

Keywords-classroom monitoring, vocabulary acquisition, cognitive psychology, cognitive semantics

\section{INTRODUCTION}

Vocabulary acquisition is attracting more and more academic concerns. Some scholars, such as Lewis(1993), believe that vocabulary acquisition is the center of second language acquisition. They think that the core of all kinds of English abilities is not the knowledge above the sentence level but language knowledge itself. In most cases, vocabulary is the carrier of notions formed when people express what they cognize the world, while notions solidify people' cognition about the world with the vocabulary as its carrier. Therefore, the cognitive-semantic study is becoming more and more popular especially in the vocabulary field. Effective classroom vocabulary teaching not only can enlarge students' vocabulary and improve their lexical competence, but also lead them to the proper way of learning language. Classroom monitoring of vocabulary acquisition based on cognitive-semantic study ensures the second language acquisition.

\section{SOME BASIC AND RELATED THEORIES}

\section{A. Lexical Semantics}

Cruse studies the meaning of words out of the perspective of lexical semantics in his book Lexical Semantics published in 1986, which takes the meaning of words as whole system and establishes the groundwork of the development of lexical semantics. The researching about the lexical semantics achieve great success. Such as Nation (2001)、Lipka(2002)、Finkbeiner, M.\& J. Nicol.(2003)、 Snyder(2007). They have developed lexical semantics theory together, which discusses the connection between the inherent property and the external facts from different views of cognition、pragmatics、 the relationship between syntax and semantic relevance v corpus and the internal structure of a word. "Lexical semantics will become distinguished among linguistic researching and play very important role in the language teaching and learning” (Wangwenbin, 2009: 8)

\section{A. Cognitive Semantics}

From the beginning of 1980', many researchers study linguistic problems by linking semantics and cognition together, such as Leonard Talmy (2000). Gradually, Cognitive semantics has formed and developed. Cognitive semantics theories believe that semantic meaning is compounded through people' psychological space. Cognitive semantics is based on the cognitive psychology.

\section{B. Cognitive Psychology}

Cognitive psychology is one of the educational psychology, which has been defined in many different ways. One of these definitions offered by Kaplan(1990) describes it as the application of psychology to education by focusing on the development, evaluation and application of theories and principles of learning and instruction that can enhance lifelong learning. Cognitive psychology is concerned with the way in which the human mind thinks and learns. Cognitive psychology is interested in the mental processes which are involved in learning. This includes such aspects as how people build up and draw upon their memories and the ways in which they become involved in the process of learning. (Williams\&Burden, 2000).

\section{IMPLICATIONS FOR CLASSROOM MONITORING}

\section{A. Monitoring Classroom Activities By Teacher}

- Design Classroom Surroundings

Classroom surroundings refer to the atmosphere for carrying out classroom activities, especially the good relationship between teacher and students. Classroom surroundings are the ultimate source which has great influence on the quality of education. To achieve the satisfactory teaching effect, the teacher needs to guide students to set up successful classroom together. It includes two dimensions. One is considered as a whole system of the role play 、 the role expectation、 code of conduct and the restriction mechanism. The another is the emotional dimension, including satisfaction 、intimacy and friction in class. For example, the teacher should ask students questions separately as well as wholly in class according to different assignment so as to put some pressure to students. Meanwhile, the teacher should pay close attention to psychological states of students and be kind to every student. 
The teacher also should enlighten the student properly if the student couldn't answer the question. The more powerful the teacher controls the classroom interaction, the more active the students are in the classroom surroundings. The requirement of designing sound classroom surroundings, which create a relative comfortable atmosphere and make students participate in the vocabulary acquisition actively instead of passively, reflects the cognitive notion because the students behave themselves as the cognitive subjects.

- Arrange Reasonable Vocabulary Teaching Steps

The reasonable arrangement provides students with opportunity to think 、 participate and reflect. Meanwhile , the teacher needs to sum up and evaluate the students behavior in the learning process, which feeds back 、 encourages and promotes both teaching and learning. To evaluate students' achievement is one of the very important classroom monitoring steps. This step should be prompt and clear to make sure the classroom teaching go ahead smoothly and effectively. Usually, there are six vocabulary teaching steps, showing as "Fig.1"

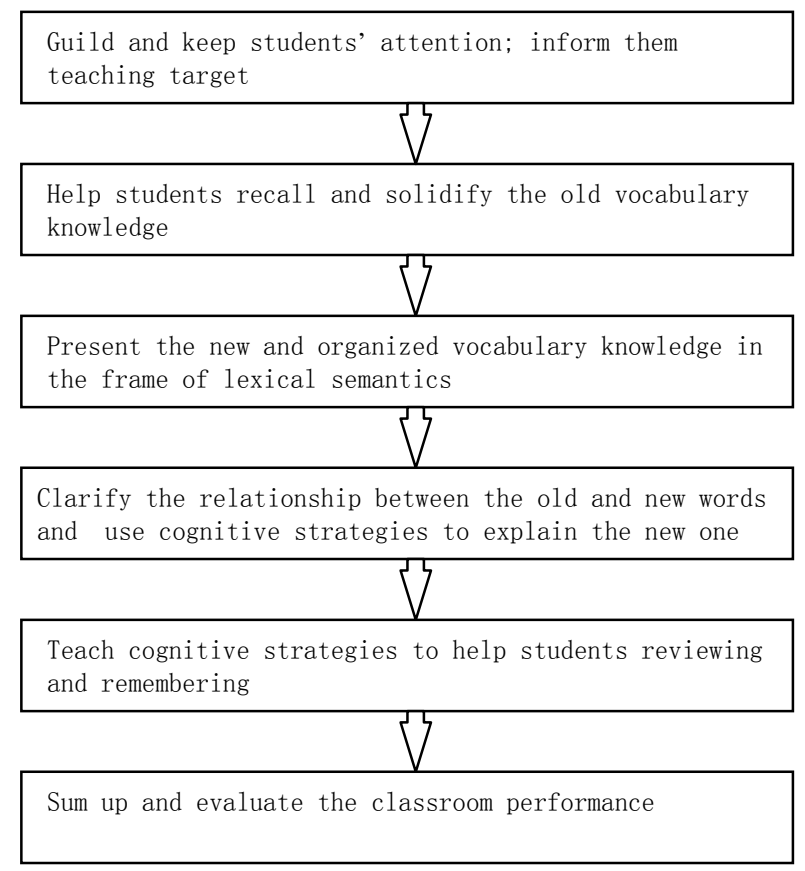

Figure 1. Example of Vocabulary Teaching Steps

- Introduce Some Vocabulary Learning Strategies And Use Some Teaching Methodology Accordingly

Strategies have become more and more popular in language learning. They can help learners learn vocabulary more effectively. Therefore, it's very necessary to introduce some vocabulary learning strategies in the frame of cognitive theory.

As one of those cognitive psychology theories, information processing theory is concerned with the process in which people receive, deal with and apply the information they've got. The exertion of the information processing in vocabulary teaching can be represented as the process of helping the students memorize, store and recollect the vocabulary. According to the information processing theory and the nature of memory, the deeper the processing, the more durable the memory of the item processed. So, in vocabulary teaching, the teachers should help the students to transfer the vocabulary from surface-level into the depthlevel purposefully. To accomplish the purpose, the teachers should use some teaching methodology and strategies designedly, such as placing the new words into a context, making vocabulary cards, etc.

During the process of teaching, the teacher should help students build up their own psychological lexical field. That means high-frequency lexical items should be taught first, because of their role in conveying a message. It is worth noting that the core-word method of teaching vocabulary should not be neglected for its obvious advantages to understand the gist. The core word allows for economy of stored representations, such as the stem for a number of (stem-) related words needs only be specified once for all. These core words could be used as the basis for a vocabulary journal, with students adding new encounters with these roots and prefixes. The teacher explains the etymological information to students and helps students predict or guess what a word means, explaining why a word is spelt the way it is, and remember the word by knowing how its current meaning evolved from its metaphorical origins. Usually English teachers have their core words according to their experience and the teaching requirement . The teacher may ask students to work in pairs to share their insights and build a collective picture of what they have been looking for. For example, if the word "respect' is taken as the core word, then the students will be taught to pay attention to its stem "spect" (spect=see; look), and they will learn to form their lexical field about "spect-". Showing as "figure2.":

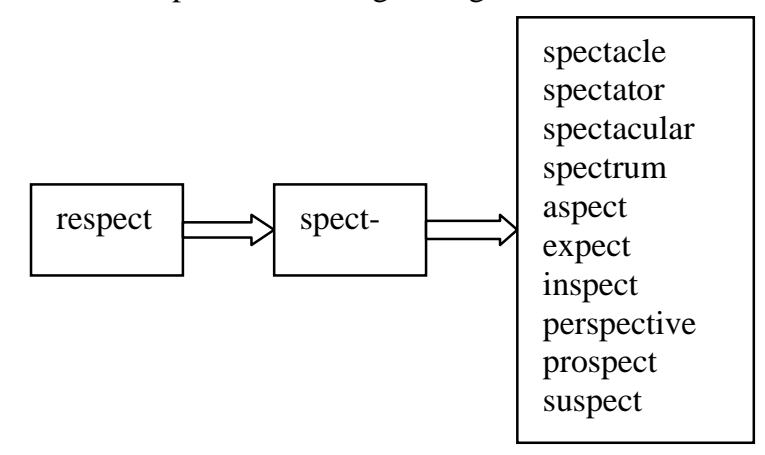

Figure 2. Example of Building up Lexical Field

As to the mastery of polysemy, the teacher not only should teach students with the infusion way of vocabulary teaching, such as English-Chinese translation 、 making examples , rote-learning and exercises, etc., but also teach them with the introduction of relevant knowledge about cognitive strategies such as metaphor and conceptual mapping, etc. An easy-to complex process in polysemy teaching and learning should be developed from the prototypical meaning to the extended meaning. 


\section{B. Monitoring Classroom Activities By Students}

- In the cognitive approach, the learner is seen as an active participant in the learning process, using various mental strategies in order to sort out the system of the language to be learned.(Williams\&Burden, 2000). Monitoring classroom activities by students includes three points, showing as figure 3 .:

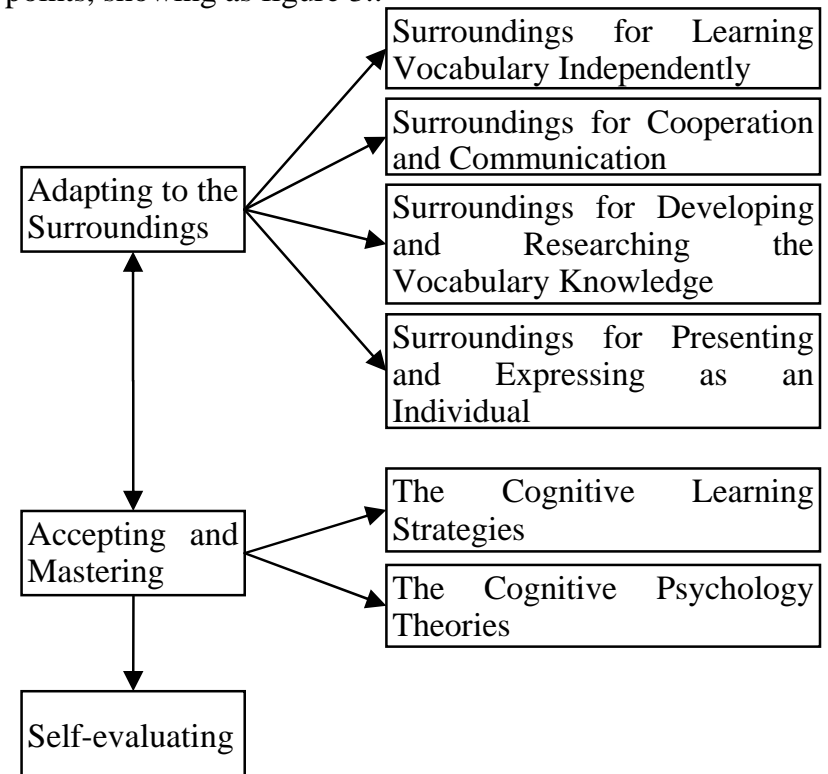

Figure 3. Example of Monitoring Classroom by Students

- Vocabulary learning involves the use of individual learning techniques especially from the point of cognitive psychology. Students need to develop their cognitive awareness of their own learning process. Students should get the knowledge about cognition .They should know the factors which affect the process and the consequence of people' cognitive activities as well as know their own limitation properly. With the teacher's instruction, the students know it's important to pay their attention to the cognitive activities and they will be active in classroom. The students should try to master the semantic relationship between words after being taught the cognitive semantics theories. Many researches show that by their own classroom monitoring, the students succeed in transferring the knowledge of passive vocabulary to active vocabulary. Therefore the students should monitor classroom activities by themselves, evaluating their own success in using learning strategies. Activities used to develop students selfevaluation insights include self-questioning , feeding back and discussing after using learning strategies. The students are the decisive factor in the vocabulary acquisition process for they are the main cognitive participants. It's very necessary for them to adjust their behavior and psychology in classroom.

\section{CONCLUSION}

Classroom monitoring vocabulary acquisition not only attaches importance to the progress of cognition, but also to the development of students. With the teacher' guidance, students must realize self-monitoring, master cognitive learning strategies and develop positive learning attitudes and habit.

\section{REFERENCES}

[1] Ellis,R. The Study of Second Language Acquisition [ M]. Oxford: Oxford University Press,2003.

[2] Finkbeiner , M. \& J . Nicol.. "Semantic category effects in second language word learning . A pplied Psycholinguistic 2003

[3] Hanks, P. Lexicology : Critical Concepts in Linguistics [ C] . London: Routledge, 2008.

[4] Hulstijn,J.H..Mnemonic methods in foreign language vocabulary learning. InCoady,J.\&T.Huckin(Eds.) ,Second Language Vocabulary Acquisition..Cambridge:Cambridge University Press. 1997

[5] Kaplan. P. S.. Educational Psychology for Tomorrow's teacher. St Paul, MN:West. 1990 。

[6] Leonard Talmy .Toward aCognitive Semanstics (Volume I 、 II) [M] The MIT Press,2000

[7] Lewis,Michael.The Lexical Approach:The State of ELT and the Way Forward [M]. Hove and London, England:Language Teaching Publications.1993.

[8] Lipka, L. English Lexicology : Lexical Structure, Word Semantics and Word Formation [ M ] . 2002.

[9] Marion Williams, \& Robert L. Burden: Psychology for Language Teachers: A Social Constructivist Approach[M] Cambridge University Press. 2000。

[10] Nation, I. P..Learning Vocabulary in Another Language. Cambridge: Cambridge University Press. 2001

[11] O’Malley,J.M.\&A.U.Chamot.. Learning Strategies in Ssecond Language Acquisition.Cambridge:Cambridge University Press. 1990

[12] Oxford,R.L. Language Learning Strategies:What Every Teacher Should Know. Boston: Heinle., 1990.

[13] Singleton, D. Language and the Lexicon [ M] . London: Arnold, 2000

[14] Snyder, J. E. Lexical Semantics:Extraordinary Words for Extraordnary Peop le[M ] . B row nWalker Press, 2007.

[15] Wang,L. Modern Foreign Language Teaching in Chinese. [ M] Shanghai: Shanghai Foreign Language Education Press. 2000.

[16] Wang, W. Cognitive Construction and Interpretation over Metaphor [ M] Shanghai: Shanghai Foreign Language Education Press. 2007.

[17] Wen,Q. English Learning Strategy In Chinese [M ) .Shanghai: Shanghai Foreign Language Education Press. 1996. 